\title{
Potential impact of chemical prophylaxis on the incidence of gonorrhoea
}

\author{
T. Y. LEE, H. M. D. UTIDJIAN, B. SINGH, U. CARPENTER, AND J. C. CUTLER \\ Graduate School of Public Health, University of Pittsburgh
}

One of the major world-wide public health problems today is the rapidly rising incidence of venereal disease combined with the increase in unwanted and casual pregnancies.

For example, in the U.S.A., an incidence of 137 cases of gonorrhoea per 100,000 in 1957 had risen to 307.5 per 100,000 in 1971 . The current epidemic has made gonorrhoea the leading reportable communicable disease in the U.S.A. Also, it is well known that the actual number of cases of gonorrhoea is almost four times the total number reported to health authorities by all sources.

For years, attempts at 'controlling' gonorrhoea were abandoned in favour of 'treating' it out of existence with increasingly larger doses of penicillin. A decade ago, the less sensitive strains requiring 0.1 unit of penicillin per $\mathrm{ml}$. for inhibition in vitro were extremely rare in clinical practice, but strains requiring 0.5 unit of penicillin per $\mathrm{ml}$. are now common. Today, many strains of gonococci are so resistant to penicillin, that a dose so large as to approach the outer limits of safety is required to effect a cure (Goldstein, 1972). Another major problem in controlling gonorrhoea is the existence of a large number of unidentified asymptomatic females (estimated as 640,000 to 1 million). A small change in the percentage of these females will produce significant changes in the prevalence of gonorrhoea. The task of eliminating gonorrhoea can therefore be simplified by making prophylactic measures as well as medical treatment available to those at risk. Parallel examples are smallpox and measles which have been brought under control by surveillance and vaccination. There are, however, fundamental obstacles to the development of an effective vaccine against gonorrhoea.

Recent work has shown that some of the intravaginal birth control compounds used by women also

Received for publication May 16, 1972

Address for correspondence: Mr T. Y. Lee, Graduate School of Public Health, University of Pittsburgh, Pittsburgh, Pa. 15123, U.S.A. This investigation is supported by the Agency for International Development under contract A.I.D./csd-2822. kill N. gonorrhoeae and T. pallidum (Arnold and Cutler, 1970; Singh, Cutler, and Utidjian, 1972; Cutler, Utidjian, Singh, and Arnold, 1973). At the 1971 American Public Health Association meeting in Minneapolis, it was reported that many such compounds 'show promise' of being extremely useful in the battle to bring venereal disease under control.

The purpose of this paper is to illustrate by using a theoretical model that a dramatic change in the prevalence of gonorrhoea is possible if topical V.D. prophylaxis is incorporated into existing V.D. control programmes and is accepted by the population at risk. In an attempt to evaluate the expected effectiveness of a prophylactic intravaginal compound in reducing the incidence of infection, a stochastic statistical model has been constructed. This model predicts the change in the national incidence of gonorrhoea for various degrees of effectiveness of the compound and for different proportions of usage by potential subjects at risk.

\section{Method}

THE MODEL

The reported total number of cases of gonorrhoea in the U.S.A. in 1957 was 216,476 , and since then the figure has increased exponentially to 624,371 in 1971 , with an average rate of increase of from 8 to 15 per cent. per year. Dynamic modelling theory indicates that any exponentially growing quantity is somehow involved with a positive feedback loop which is sometimes described as a "vicious circle" (Meadows, Meadows, Randers, and Behrens, 1972). For example, an increase in new gonorrhoea infections will lead in turn to a further increase in the incidence of new infections.

Several definitions must be presented to comprehend the model which is to be described:

(1) Define a generation for a patient with gonorrhoea as the interval between the time at which the individual acquires an infection and the time that the individual becomes potentially infectious to another through sexual contact. The average incubation period for $N$. gonorrhoeae in the male is about 3 to 5 days. It, can, therefore 
reasonably be assumed that a generation is about 7 days (incubation + average time for next sex act) for the male.

The generation time for the female may be shorter. The term 'incubation period' is scarcely applicable to the female with respect to gonorrhoea, in that 80-85 per cent. of females show no symptoms for many months-if at all. Moreover, the female may transmit infection as a passive mechanical vehicle of infectious material within minutes of the deposition of fresh material (i.e. by coitus with an infectious male) in the vaginal vault. This passive transmission may operate for several hours and may be significant in the case of a prostitute or highly promiscuous female.

(2) Let $x(\mathrm{t})=$ total national cases of gonorrhoea at time $\mathrm{t}$, where $0 \leq \mathrm{t}<\infty$. Then $x(0)=$ the total cases of gonorrhoea at the time prophylaxis is initiated.

(3) Define $\lambda$ as the average risk of an uninfected person acquiring gonorrhoea by sexual contact with an infected person during a generation.

(4) Define $\mu$ as the overall rate of loss of infectiousness whether by treatment or spontaneous cure during $a$ generation.

(5) Define $k$ as the proportion of individuals at risk prevented from acquiring a gonococcal infection in a generation by a prophylactic compound, assuming that each individual uses the compound before each act of coitus.

(6) Define $p$ as the proportion of population at risk using the prophylactic compound before each act of coitus. Therefore $[(1-p k) \lambda]$ is the risk of acquiring gonorrhoea by sexual contact per generation, taking into account the effectiveness of the prophylactic compound used and the proportion of those at risk using it.

(7) From the above descriptions, the expected total number of cases of gonorrhoea at the time $t$ is derived as

$$
\mathrm{E}[x(\mathrm{t})]=x(0) \cdot \exp [(1-p k) \lambda-\mu] \mathrm{t} .
$$

RISK OF ACQUIRING GONORRHOEA BY SEXUAL CONTACT WITH INFECTED CASES IN A GENERATION

A recent paper (Holmes, Johnson, and Trostle, 1970) reported that the estimated average risk to crewmen from an aircraft carrier while on 6 days shore leave in the Philippines of acquiring gonorrhoea from infected females was approximately 22 per cent. According to other investigators (Cutler, 1971; Boulton, 1970; Fiumara, 1971), the risk of contracting gonorrhoea on sexual exposure with an infected partner ranges from 5 to 40 per cent. Therefore, for both sexes, the overall average risk of acquiring gonorrhoea by sexual contact with an infected partner is estimated to be 27 per cent.

OVERALL RATE OF LOSS OF INFECTIOUSNESS BY TREATMENT AND SPONTANEOUS CURE DURING A GENERATION

It is known that the rate of loss of infectivity by treatment and spontaneous cure varies considerably between the sexes. However, when this rate is considered from the point of view of the prevalence rate and in terms of a generation as defined above, it is estimated to be approximately $26 \cdot 7$ per cent. per generation.

\section{Results}

By employing the model $\mathrm{E}[x(\mathrm{t})]=x(0)$. exp $[(1-p k) \lambda-\mu] \mathrm{t}$, the significant effect of prophylaxis when merged into the existing venereal disease programme can be seen from Tables I, II, and III.

Table I shows that, if there is no significant change in VD control programme and the rate of increase remains the same as in the past several years, there will be 1,169 cases by the end of 52 generations (that is 1 year), a 17 per cent. increase over that of 1 year ago. On the contrary, if there is a prophylactic

T A B LE I Expected total number of cases of gonorrhoea at the end of different generations (starting with 1,000 cases $\left.{ }^{\star}\right)$

\begin{tabular}{|c|c|c|c|c|c|c|c|c|c|c|c|}
\hline \multirow{2}{*}{$\begin{array}{l}\text { Effectiveness } \\
\text { of product } \\
\text { (k) }\end{array}$} & \multirow{2}{*}{$\begin{array}{l}\text { Proportion } \\
\text { of usage } \\
\text { (p) }\end{array}$} & \multicolumn{10}{|c|}{ Generation $^{\mathrm{a}}$} \\
\hline & & 1 & 5 & 10 & 20 & 30 & 40 & 52 & $\begin{array}{l}2 n d \\
\text { Year }\end{array}$ & $\begin{array}{l}3 r d \\
Y e a r\end{array}$ & $\begin{array}{l}4 t h \\
Y e a r\end{array}$ \\
\hline 0.50 & $\begin{array}{l}0 \\
0 \cdot 20 \\
0 \cdot 25 \\
0 \cdot 30\end{array}$ & $\begin{array}{r}1,003 \\
976 \\
969 \\
963\end{array}$ & $\begin{array}{r}1,015 \\
886 \\
856 \\
831\end{array}$ & $\begin{array}{r}1,031 \\
786 \\
733 \\
690\end{array}$ & $\begin{array}{r}1,061 \\
618 \\
537 \\
477\end{array}$ & $\begin{array}{r}1,094 \\
486 \\
394 \\
329\end{array}$ & $\begin{array}{r}1,127 \\
323 \\
289 \\
227\end{array}$ & $\begin{array}{r}1,169 \\
286 \\
199 \\
146\end{array}$ & $\begin{array}{r}1,366 \\
82 \\
39 \\
21\end{array}$ & $\begin{array}{r}1,597 \\
24 \\
7 \\
3\end{array}$ & $\begin{array}{r}1,860 \\
7 \\
1 \\
0\end{array}$ \\
\hline 0.60 & $\begin{array}{l}0 \\
0 \cdot 20 \\
0 \cdot 25 \\
0 \cdot 30\end{array}$ & $\begin{array}{r}1,003 \\
970 \\
963 \\
955\end{array}$ & $\begin{array}{r}1,015 \\
860 \\
831 \\
794\end{array}$ & $\begin{array}{r}1,031 \\
740 \\
690 \\
631\end{array}$ & $\begin{array}{r}1,061 \\
548 \\
477 \\
398\end{array}$ & $\begin{array}{r}1,094 \\
406 \\
329 \\
251\end{array}$ & $\begin{array}{r}1,127 \\
301 \\
227 \\
158\end{array}$ & $\begin{array}{r}1,169 \\
210 \\
146 \\
91\end{array}$ & $\begin{array}{r}1,366 \\
44 \\
21 \\
8\end{array}$ & $\begin{array}{r}1,597 \\
9 \\
3 \\
1\end{array}$ & $\begin{array}{r}1,860 \\
2 \\
0 \\
0\end{array}$ \\
\hline $0 \cdot 70$ & $\begin{array}{l}0 \\
0 \cdot 20 \\
0 \cdot 25 \\
0 \cdot 30\end{array}$ & $\begin{array}{r}1,003 \\
965 \\
956 \\
947\end{array}$ & $\begin{array}{r}1,015 \\
839 \\
802 \\
763\end{array}$ & $\begin{array}{r}1,031 \\
704 \\
644 \\
582\end{array}$ & $\begin{array}{r}1,061 \\
496 \\
414 \\
339\end{array}$ & $\begin{array}{r}1,094 \\
349 \\
267 \\
197\end{array}$ & $\begin{array}{r}1,127 \\
246 \\
172 \\
115\end{array}$ & $\begin{array}{r}1,169 \\
162 \\
101 \\
60\end{array}$ & $\begin{array}{r}1,366 \\
26 \\
10 \\
4\end{array}$ & $\begin{array}{r}1,597 \\
4 \\
1 \\
0\end{array}$ & $\begin{array}{r}1,860 \\
0 \\
0 \\
0\end{array}$ \\
\hline
\end{tabular}

$\star x(0)=1,000$ is an arbitrary figure chosen for convenience

a The 52nd generation means the end of 1970. $\lambda=0.27 \mu=0.267$

2nd year means the end of 1971

3rd year means the end of 1972

4th year means the end of 1973 
TABLE II Expected total number of cases of gonorrhoea in the U.S.A. at different times (reported cases ${ }^{\star}$ )

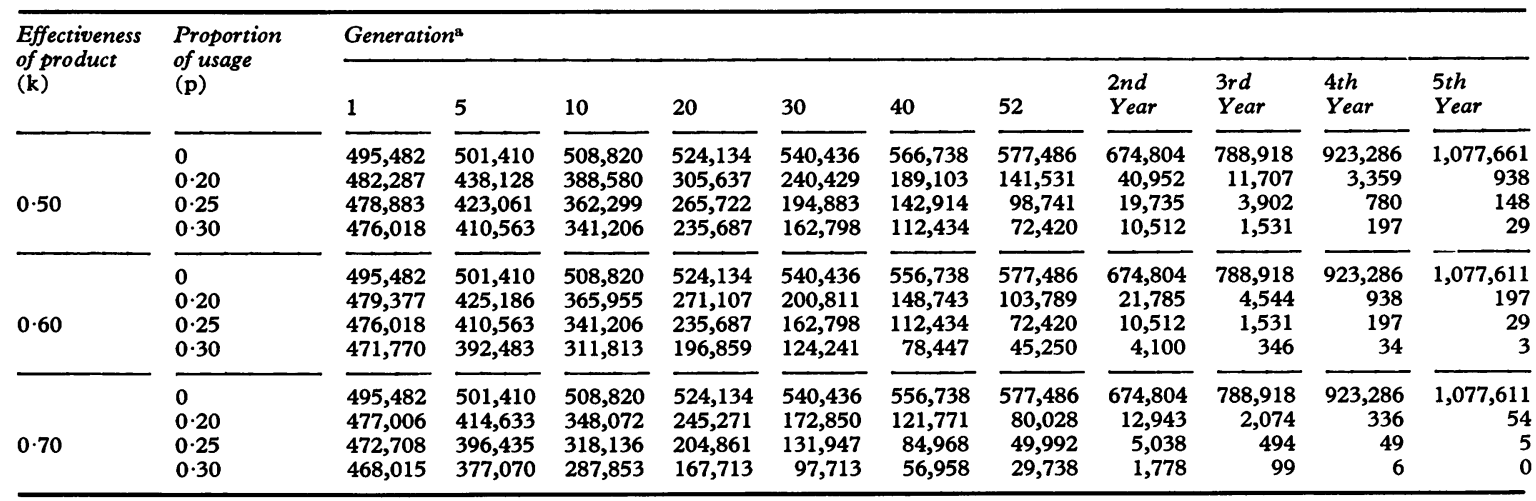

$\star_{x}(0)=494,000=$ national total of cases reported in 1969. $\lambda=0.27 \mu=0.267$

a52nd generation means the end of 1970

2nd year means the end of 1971

3rd year means 1972

4th year means 1973 and

5 th year means 1974

TABLE II I Expected total number of cases of gonorrhoea in the U.S.A. at different times (including non-reported cases ${ }^{\star}$ )

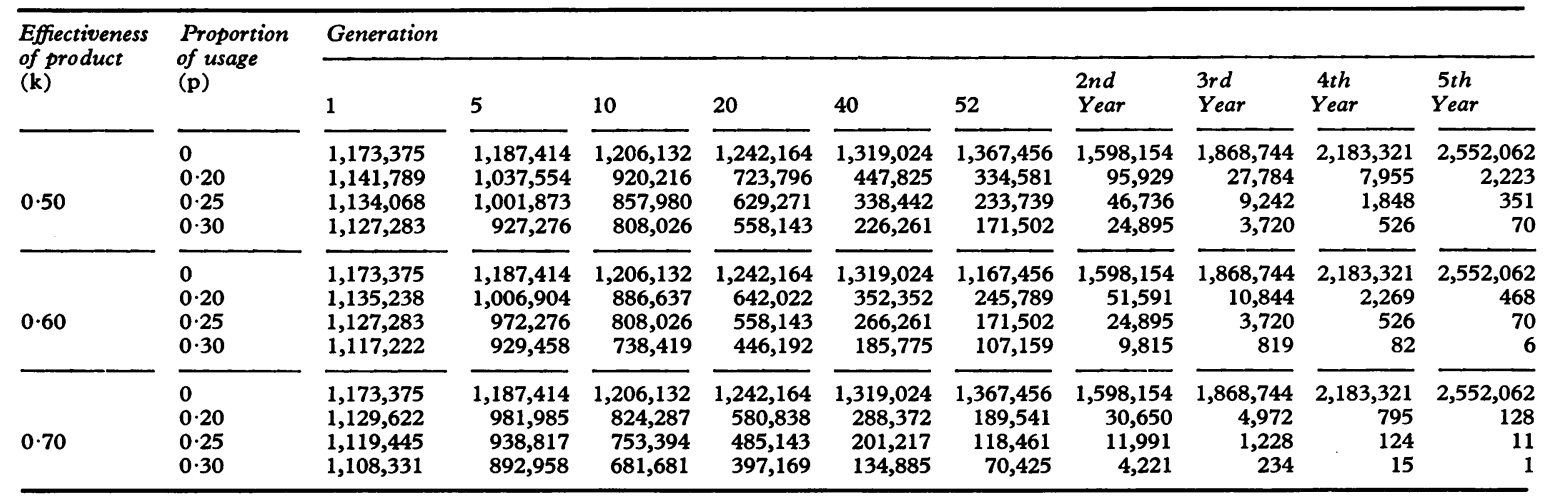

${ }^{\star} x(0)=1,169,866=$ national total cases adjusted for under-reporting in 1969. $\lambda=0.27 \mu=0.267$

compound which is only 50 per cent. effective against Neisseria gonorrhoeae and which is used by 25 per cent. of the subjects at risk before every act of coitus, then it will take a little more than 4 years to eliminate all 1,000 cases to start with. This is a dramatic decrease. Further trends of change under different assumptions of effectiveness of the prophylactic product and the proportion of usage by potential subjects at risk are also presented in Table $I$.

The same calculations can be carried out for the reported cases of gonorrhoea in the U.S.A. The expected number (Table II) is based on the national total of approximately 494,000 cases reported in the U.S.A. in 1969. Again, assuming no significant changes in venereal disease prevention and treatment programmes, a statistical projection using the model gives totals of 577,486 cases in 1970 , increasing to 674,804 cases in 1971. The actual totals reported were 573,200 and 624,371 for 1970 and 1971 respectively. According to the present projection, by the end of 1974 the total cases reported will exceed one million if there is no major change in existing public health prevention programmes.

By contrast, Table II shows the value of prophylactic measures, and the trend towards a decreasing number of infections with different degrees of effectiveness of the prophylactic compound and different proportions of usage. If the reported cases of gonorrhoea were the cases actually existing in the U.S.A. and if an effective prophylactic 
programme had been introduced at the beginning of 1969 , it might have eliminated virtually all the 494,000 cases by the end of 1974 (assuming 70 per cent. effectiveness of the prophylactic and 30 per cent. usage by subjects at risk).

The main objective of a venereal disease prevention programme should be to prevent the sexually active from contracting gonorrhoea and finally to eliminate this disease from the population. The non-reporting of cases by private physicians always presents a difficult problem for the programme planner organizing various preventive activities. It has been suggested that the number of persons treated for gonorrhoea is three or four times the number reported. Also, despite their value, cultures are positive only in about 70 per cent. of female contacts of known cases of gonorrhoea (Pariser, 1971). A preventive programme can succeed only by treating those exposed to risk of infection, whether clinical symptoms or positive cultures are present or not. Another approach could be tried by making available to subjects at risk pre-coital prophylactic products that will prevent them from becoming infected. With this in mind, Table III was compiled, using as the initial number the cases of gonorrhoea for $1969(1,169,866)^{\star}$ as obtained by adjusting for under-reporting by private physicians. The merit of the prophylactic approach is self-evident from this Table. If the upward trend remains as it is, there will be over 2.5 million cases of gonorrhoea by the end of 1974. But gonorrhoea could be almost completely eliminated by the same date if only 30 per cent. of the population at risk would use a prophylactic product which was only 70 per cent. effective.

\section{Discussion}

All the information used for defining the risk of acquiring venereal disease by sexual contact during a generation was obtained indirectly at different places and different times under diverse circumstances. However, it is felt that the range of 5 to 40 per cent. with an average of about 27 per cent. will not differ too much from the true risk. It should be pointed out that a prophylactic programme alone cannot be expected to eliminate the gonorrhoea epidemic. Its greatest value will be obtained only by incorporating it into the existing programme of treatment and education.

Active measures must be taken to encourage a greater sense of responsibility and desire for cooperation on the part of potential patients in protecting themselves through the practice of prophylaxis. If they do not accept this responsibility, our experience

^See Appendix suggests that there will be a massive increase in the prevalence of gonorrhoea with a corresponding need for public health manpower for case finding and treatment. Without ever increasing health expenditure, the incidence of gonorrhoea will certainly continue to rise (Cutler, 1972).

\section{Summary}

Research is being conducted at the Graduate School of Public Health, University of Pittsburgh, to evaluate the prophylactic efficacy against the commoner venereal diseases of several vaginal chemical contraceptives in common use.

Using the average risk of contracting gonorrhoea from sexual contact and the estimated true prevalence of gonorrhoea in the total population of the United States, a stochastic model was developed to predict the epidemiological impact of such prophylaxis at various hypothetical levels of effectiveness and of population usage. Even if a topical prophylactic is only 50 per cent. effective and only 25 per cent. of the population at high risk use it for every act of coitus, one can expect a dramatic decrease in the incidence of gonorrhoea within a short period of time. It is apparent from the model that the longer the delay in initiating prophylaxis programmes the longer will it take to bring the disease under control.

We wish to express our deep appreciation to Mrs Carole Ferson, who put so much patient untiring effort into the preparation of the original manuscript.

\section{References}

Arnold, R. C., and Cutler, J. C. (1970) Publ. Hlth Rep. (Wash.), 85, 1062

Boulton, H. A. (1970) Brit. F. vener. Dis., 46, 106

CUtLER, J. C. (1971) 'The Role of Prophylaxis'. International VD Symposium, p. 29 (1972) 'The Future of Prophylaxis in VD Control'. International VD Symposium. (in press)

-, Utidjian, H. M. D., Singh, B., and ARnold, R. C. (1973) Milit. Med., -, (in press)

Fiumara, N. J. (1971) 'Modern-Age Complications of VD'. International VD Symposium, p. 33

Goldstein, H. (1972) Amer. Druggist, 165, Jan. 10, p. 51

Holmes, K. K., Johnson, D. W., and Trostle, H. J. (1970) Amer. F. Epidemiol., 91, 170

Meadows, D. H., Meadows, D. L., Randers, J., and BeHRENS, W. W. (1972) 'The Limits to Growth'. A report for the Club of Rome's project on the predicament of mankind. A Potomac Associates Book. Univers Books, New York

Pariser, H. (1971) 'Asymptomatic Gonorrhoea'. International VD Symposium, p. 26

Singh, B., CutleR, J. D., and Utidjian, H. M. D. (1972) Brit. F. vener. Dis., 48, 47 


\section{APPENDIX}

Total number of cases of gonorrhoea (reported + non-reported) in 1969.

(a) The reported number of cases in the U.S. population in 1969 was 494,227.

(b) In 1969, about 28 per cent. of reported cases of gonorrhoea were contributed by private physicians.

(c) In 1968 a survey by the American Social Health Association revealed that private physicians were reporting only 17 per cent. of cases of gonorrhoea treated by them.

(d) Total U.S. cases of gonorrhoea in 1969 adjusted for under-reporting by private practising physicians was derived as:

$$
\begin{aligned}
& 494,227 \times 28 \text { per cent. }=138,384 \\
& 138,384 \div 0 \cdot 17=814,023 \\
& 814,023+(494,227-138,384)=1,169,866
\end{aligned}
$$

\section{Action possible de la prophylaxie chimique sur l'incidence de la gonococcie}

Une recherche a été entreprise à la Graduate School of Public Health, Université de Pittsburg, pour estimer l'action prophylactique, contre les maladies vénériennes communes, de plusieurs contraceptifs chimiques vaginaux d'emploi courant.

En se fondant sur le risque moyen de contracter la gonococcie par contact sexuel et sur la prévalence réelle estimée des gonococcies dans la population totale des Etats-Unis, un modèle stochastique fut établi pour prévoir l'influence épidémiologique d'une telle prophylaxie à des niveaux hypothétiques variés d'efficacité et selon l'usage fait par la population. Même si la prophylaxie des maladies vénériennes par un topique n'a qu'une action de 50 pour cent et même si 25 pour cent seulement de la population hautement exposée l'utilise à chaque coït, on peut s'attendre à une nette et rapide diminution de l'incidence de la gonococcie. Le modèle montre que plus long sera le moment de mise en place des programmes de la prophylaxie de la gonococcie plus longtemps il faudra pour arriver à contrôler la maladie. 